\title{
A PLURALIDADE COMO IDÉIA REGULADORA: A NOÇÃO DE JUSTIÇA A PARTIR DA FILOSOFIA DE LYOTARD
}

\author{
Karla CHEDIAK $^{1}$
}

- RESUMO: De acordo com Lyotard, não poderíamos mais contar com o apoio de um sistema filosófico para fundamentar nosso conceito de justiça. A pluralidade é a grande marca da experiência do pensamento no nosso tempo e, por isso, deveríamos considerar o problema da justiça a partir dessa pluralidade e não contra ela. Isso não significa reduzir a questão da justiça ao jogo de opinião e das relações de dominação, mas significa concebê-la a partir de uma Idéia que é capaz de reconstituir a universalidade e também a finalidade na forma da coexistência das diferenças. Essa Idéia teria uma função reguladora sobre a diversidade das opiniões e se basearia no fato de que o julgar transcende a determinação do presente, pois projeta o porvir da humanidade. Se, por um lado, a Idéia é incapaz de gerar um conceito unitário de justiça, capaz de garantir a paz entre os diferentes, por outro, ela, ao menos, evita que se confundam unificação e dominação, promovendo acordos que sustentem a coexistência das diferenças.

- PALAVRAS-CHAVE: Justiça; Kant; Lyotard; pluralidade.

Quando refletimos sobre a questão da justiça, algumas associações são feitas quase intuitivamente, tais como a de equilíbrio entre as partes, princípio de igualdade, distribuição eqüitativa, mas logo as dificuldades se mostram, já que a nossa sociedade, sendo bastante diversificada, apresenta uma heterogeneidade tanto em termos das diversas culturas que coexistem em um mundo interligado como em relação aos modos de vida

1 Professora Adjunta - Departamento de Filosofia - UERJ - 20550-900 - Rio de Janeiro - RJ. 
e aos valores que surgem no interior de uma mesma sociedade. A questão de que trataremos diz respeito à possibilidade de se desenvolver uma compreensão de justiça a partir da perspectiva de uma sociedade profundamente diversificada.

Essa não é uma tarefa fácil, principalmente se considerarmos que o conceito de justiça supõe tomar como iguais por natureza os seres de que estamos tratando (Bobbio, 1996, p.24). Ser igual por natureza implica que possamos determinar qual característica, dentre as muitas que há em comum entre os humanos, deve ser entendida como essencial para se fundamentar nela o conceito de justiça. Por exemplo, o homem é um animal bípede, disse-nos Aristóteles, mas dificilmente essa qualidade seria considerada suficiente para basearmos nossa concepção de justiça. $\mathrm{O}$ homem é um ser racional, disse-nos ainda o filósofo, e essa foi considerada uma característica suficientemente boa para tal fim. Ela levanta, no entanto, outros problemas bem complicados, como o de saber o que é a razão e o modo como ela foi concebida, se, ao longo da história, o foi de uma única maneira ou de maneiras diferentes. Há, ainda, o problema de saber se há uma forma de organização social que teria o privilégio de estabelecer o conceito de razão e se, apesar disso, a razão estaria expressa em todas as formas culturais e sociais, mesmo naquelas que desconhecem ou desconheceram na sua origem esse conceito. O que importa é que a noção de justiça, nessa perspectiva, supõe a igualdade entre os seres considerados e exige a especificação da qualidade que torna esses seres iguais, e essa seria a sua determinação fundamental.

Em seu texto "Kant the liberal, Kant the anarchist", Todd May (1990, p.256), tomando Kant como ponto de partida, caracteriza justiça a partir de três aspectos: o primeiro mostra que justiça diz respeito às relações entre as pessoas; o segundo, que as pessoas são seres de vontade e o terceiro aspecto mostra que a justiça tem de se aplicar a todas as vontades, não podendo basear-se no desejo de cada um, mas na unidade de todas as vontades. A noção de justiça supõe, então, a pluralidade dos seres de vontade, como seres livres, e expressa uma relação de equilíbrio entre essas vontades, equilíbrio esse que só pode ser alcançado se essa multiplicidade tiver um ponto de convergência, de unidade, que, nesse caso, é exatamente o que caracteriza esses seres como livres. É possível, segundo Kant, conceber-se um princípio geral de justiça que diz o seguinte: "toda ação é justa se nela, ou em sua máxima, a liberdade da vontade de cada um puder coexistir com a liberdade de todos de acordo com a lei universal" (ibidem, p.527). A noção de justiça surge num contexto de pluralidade, de vontades divergentes, como podemos observar na expressão acima - vontade de cada um - e ela se dá, desde que seja 
encontrada a unidade nessa multiplicidade, o que ocorre quando é estabelecida uma regra que valha para todas as vontades. A fonte dessa unidade é a liberdade, mas considerando que ela se apresenta, nesse contexto de pluralidade, como a liberdade de cada um perante o outro, podendo, por isso mesmo, tornar-se um obstáculo para o uso da liberdade de acordo com as leis universais; desse modo, é muitas vezes requerido, para a manutenção da justiça, o uso da coerção como meio de se impor um limite às particularidades das vontades. ${ }^{2} \mathrm{O}$ importante é que o elemento universal esteja presente na unidade da razão prática, na compreensão de vontade como livre e racional.

Podemos também, a partir de uma outra posição filosófica, afirmar que a determinação dessa qualidade essencial que unifica todos os homens não é mais possível de ser concebida, pois ela, explícita ou implicitamente, supõe a existência de uma realidade essencial, da qual se origina o conceito universal de homem que serve de suporte para se construir um conceito de justiça. $\mathrm{Na}$ ausência desse suporte, o critério de igualdade não pode mais se universalizar e tornar-se absoluto e, sendo variável, é estabelecido por cada sociedade. Cada uma tem a função de definir em que situação os seres devem ser considerados iguais, demarcando, assim, um parâmetro que oriente a noção de justiça. De qualquer modo, a justiça, pensada do ponto de vista do conjunto de seres existentes considerados iguais, diz respeito ao equilíbrio das relações entre esses seres, entendidos como indivíduos. É verdade que já podemos encontrar aqui uma fragmentação na concepção de justiça, uma vez que se trata de modos diversos de se considerar a igualdade entre os homens de um determinado grupo social ou de uma sociedade particular. O problema é que essas partes não estão isoladas e que hoje observamos a mais extensa e profunda convivência de diferentes formas de organização da sociedade. Por isso, a questão insiste e se apresenta agora sob a forma da possibilidade de se estabelecer uma noção de justiça, que seja compatível com essa multiplicidade, quer de grupos diferenciados dentro de uma mesma sociedade, quer de formas de sociedade diferenciadas. A questão é política, pois o problema da unificação é historicamente também o problema das relações de poder, de dominação. É, no entanto, principalmente filosófica, uma vez que exige de nós repensar a relação entre uni-

\footnotetext{
2 "Tudo o que é injusto é um obstáculo à liberdade segundo leis universais, mas a coerção é um obstáculo ou resistência que acontece à liberdade. Por conseguinte: se um certo uso da liberdade mesma é um obstáculo à liberdade segundo leis universais (ou seja, é injusto), então a coerção, que lhe é oposta, como impedimento ao obstáculo da liberdade, está de acordo com a liberdade segundo leis universais, ou seja, é justa" (Rechtsl, v.6, p.231 apud Terra, 1995, p.81).
} 
dade e multiplicidade e elevar a questão para além do fato da dominação e seu efeitos de subordinação do outro ou mesmo de eliminação do outro. O que desejamos é tratar a questão filosoficamente, enfrentando o desafio de desenvolver uma compreensão de justiça que não se fundamente em uma concepção unitária de homem, quer seja ela fundada metafisicamente, quer seja ela baseada na unidade da linguagem. Ao contrário, partiremos da impossibilidade de se encontrar um elemento ou uma qualidade unificadora diante da multiplicidade da prática em processo de renovação permanente. No entanto, não podemos simplesmente eliminar a questão da justiça, porque lidamos com ela cotidianamente, tanto no âmbito das relações interpessoais quanto no âmbito das relações políticas, mas reconhecemos que, do ponto de vista de um pluralismo, não seria possível construírem-se referências universais para guiar nossas ações.

A proposta de Lyotard é a de repensar a relação entre justiça e pluralismo a partir do conceito de Idéia reguladora concebido por Kant. Para ele, a possibilidade de se fundamentar metafisicamente a nossa prática, isto é, de termos Deus ou uma essência como garantia da unidade e da universalidade dos nossos valores, já havia sido corroída pela crítica filosófica desenvolvida ao longo de toda a modernidade. Ela teria dado lugar a outro tipo de construção de discursos de fundamentação não mais metafísicos, mas que guardavam ainda a função daqueles, a saber, a capacidade de legitimar os nossos saberes, impedindo-os de se perderem na dispersão do horizonte meramente empírico, fossem esses saberes relacionados com o domínio cognitivo, fossem relacionados com o domínio prático. A despeito da especificidade de cada filosofia e de cada forma de saber, a concepção de história, a idéia de homem e a de progresso da humanidade assumiram papel preponderante na confiança que se depositava no futuro e nos saberes que se produziam, se acumulavam e se desenvolviam. Vários foram os motivos históricos - e não apenas filosóficos - que teriam levado à crise da fundamentação, e, conseqüentemente, à crise da idéia de progresso histórico da humanidade, dos benefícios advindos do desenvolvimento do nosso saber científico e, por fim, da própria idéia de homem.

A justificativa da perda de legitimação dos saberes é a de que haveria um enfraquecimento na credibilidade dos grandes relatos da modernidade, principalmente no relato das luzes e no relato especulativo. Podemos sintetizar essa idéia da seguinte forma: nenhum saber pode autolegitimar-se, mas deve encontrar sua legitimação em outro saber que o legitime, e quando esse outro saber não é mais capaz de se justificar perante os homens, o que vem à tona é uma situação filosoficamente pro- 
blemática, a crise da legitimação (Lyotard, 1986a, p.53). O problema da legitimação é uma questão filosófica: a da fundamentação e da justificação dos saberes; por isso, não põe em xeque a existência desses saberes, quer seja a pragmática do saber científico, quer seja a prática ética e política. Levanta, no entanto, algumas questões com relação ao reconhecimento desses domínios, tais como: será que o desenvolvimento do conhecimento científico e da tecnologia nos traz necessariamente benefícios? Talvez o desenvolvimento da história não nos esteja conduzindo para o melhor e, nesse caso, nenhuma finalidade poderia ser apreendida no seu movimento. O problema da legitimação também atinge o modo pelo qual constituímos nossos valores, pois é a filosofia a fonte legitimadora, fornecedora do suporte conceitual necessário para que determinemos em que instância os homens poderiam ser igualizados e unificados, construindo, assim, a base para um conceito universal de justiça. No entanto, na ausência desse suporte conceitual, não haveria como determinar, legitimamente, qual seria essa qualidade essencial e, toda vez que assim procedêssemos, estaríamos sob suspeita de que esse fosse apenas um meio eficaz e discreto de se exercer a dominação. Desse modo, pergunta Lyotard (1987, p.65): como saber se as guerras conduzidas pela instância singular em nome da instância universal são guerras de libertação ou de conquista? Como poderíamos, na ausência de um suporte filosófico de fundamentação, estabelecer um critério universal que nos permitiria julgar o justo e o injusto?

Lyotard vai considerar a estreita relação entre o discurso cognitivo, que pretende obter a verdade, e o poder que ele acaba conquistando, administrando e traduzindo na forma do "melhor desempenho", em que se constrói uma equação entre riqueza, eficiência e verdade. Num certo sentido, o mesmo se poderia dizer com relação ao domínio prático, pois também aí o discurso universal que visa à unidade consensual é inseparável das instâncias particulares que o veiculam, ampliando assim o seu poder. Então, teríamos de recolocar a questão da justiça sem buscar fundamentá-la em uma unidade preestabelecida, já que estaríamos pressupondo que não haveria nenhuma qualidade essencial que unificasse os homens, que pudesse desvincular-se do exercício de poder de uma instância particular.

Na verdade, o que poderíamos dizer que unifica os homens é a sua diversidade, que poderia ser detectada no atual estado de coisas, no passado e também no que ainda está por vir. A impossibilidade de se encontrar uma unidade conceitual que percorra a multiplicidade das práticas parece levar-nos a ter de abandonar a constituição de um discurso consistente sobre a justiça, fazendo-nos aceitar a redução da questão da justiça ao 
jogo de opinião e ao exercício generalizado da dominação e de sua contrapartida, a resistência. No entanto, isso parece insuficiente, pois o que acaba generalizado é que uma dada coletividade de seres humanos, organizada em torno de suas convenções particulares e de suas tradições específicas, decide sobre o que é justo em determinado momento para determinado grupo. O problema, como diz Lyotard, é que uma regra de convenção exigiria que aceitássemos, desde que houvesse unanimidade em relação a ela, qualquer coisa, até mesmo o nazismo. Nesse tipo de posição, não há lugar para qualquer julgamento do que deve ser feito e é preciso aceitar o que muitas vezes é inaceitável, exatamente porque a noção de justiça ficou reduzida à de particularidade (Lyotard \& Thébaud, 1985, p.65).

É preciso fazer um esforço para se encontrar uma forma de conceber a justiça relacionando-a com a pluralidade, mas sem reduzi-la ao jogo de opinião. Na verdade, a necessidade de se conceber o pluralismo no domínio prático nasce da impossibilidade de se fundamentar a ação prática no conhecimento. Para Lyotard, é uma questão de diferença de natureza desses discursos. $\mathrm{O}$ gênero cognitivo diz respeito ao conhecimento, à possibilidade de se atribuírem a seus enunciados valores de verdade, a saber, o verdadeiro ou o falso, e por isso tem uma natureza diferente do prescritivo e não poderia ser unificado com ele de forma harmônica, mas apenas sob a forma de subordinação. Há aqui uma concepção de linguagem que recusa a existência de uma linguagem universal, salvo como objeto de uma Idéia. A linguagem seria uma pragmática de jogos distintos intrincados numa prática social, em que alguns são identificáveis, e outros, não. Assim, não faz sentido buscar suporte para o jogo prescritivo no descritivo (Lyotard, 1983, § 95).

Traçamos, com isso, os limites dentro dos quais a questão da justiça deve ser posta. Por um lado, a recusa do convencionalismo simples, quer dizer, considerar justo o que uma determinada comunidade julga ser justo, e, por outro, a recusa de um critério objetivo que possa determinar o verdadeiro para o domínio prático. Estamos limitados pelo jogo da opinião, mas não satisfeitos com ele.

Consideremos agora a alternativa proposta por Lyotard de que é possível, a partir da noção kantiana de Idéia reguladora, recolocar a questão da justiça. Se essa não se mostrar suficiente para guiar nossa ação em cada caso específico, isso já era previsível porque estamos no reino da opinião, ou seja, das convenções, das crenças, dos hábitos etc. O que se pode esperar é que ela tenha uma função reguladora dentro de uma realidade heterogênea e que ela estabeleça uma regra de justiça que não se contraponha à própria heterogeneidade, à especificidade das conven- 
ções. Estamos no reino da opinião, mas, para termos uma noção mínima de justiça, precisamos transcender os particularismos da própria opinião e não há como fazer isso sem reconstituir um universal. Esse universal deve ter uma natureza bem especial, não podendo restabelecer uma relação do tipo gênero-espécie, ou seja, submeter os particulares a uma unidade que abarque a todos; esse universal não pode ser determinante em nenhum sentido. Ele não diz uma qualidade ou um aspecto que seja comum a todos, mas tem uma natureza supra-sensível, e isso parece adequado, uma vez que a Idéia não nos fornece um conhecimento da realidade nisso que ela é, mas pode expressar aquilo que desejamos que ela seja e, com isso, pode também transcender a opinião. A Idéia não é uma opinião, tampouco é um conceito, mas um uso ilimitado do conceito, e é por ter essa realidade diferente que ela nos permitiria alcançar uma forma de se pensar a justiça, escapando das alternativas já rejeitadas.

A Idéia não apenas introduz uma dimensão de universalidade, como também implica a noção de finalidade, que se apresenta na forma de um horizonte que se projeta, mesmo sem a certeza de que venha a se tornar realidade. Sua função seria regular as relações que se dão no presente, sem roubar do futuro a sua imprevisibilidade. Essa função reguladora não nos pode dizer o que é justo e o que não é justo para uma dada sociedade, por isso não estabelece positivamente nem valores nem princípios e deixa isso a cargo de cada grupo social, ao domínio da opinião. Sua consideração, no entanto, seria fundamental, pois, mesmo tendo uma função reguladora e não determinante, a Idéia não pode cumprir sua função sem transcender as particularidades, ou seja, sem considerar a totalidade dos seres humanos e sem projetar o horizonte da pragmática intersubjetiva.

É verdade que a Idéia, em Kant, se apresenta como a Idéia de progresso da humanidade e se sustenta na certeza de que, sendo os seres humanos racionais, há uma unidade que os atravessa e que, por isso, a Idéia não é algo gratuito e contingente. ${ }^{3}$ Nesse caso, não haveria lugar para o jogo de opiniões, não haveria de fato heterogeneidade. Podemos, no entanto, estabelecer a conexão entre a Idéia como reguladora e o domínio da opinião, desde que compreendamos que o conteúdo da Idéia não é mais o mesmo, porque é a própria pluralidade que caracteriza a experiência humana. A constituição da Idéia ainda se justifica, porque a

3 "O que se mostra confuso e irregular nos sujeitos individuais poderá ser reconhecido, no conjunto da espécie, como um desenvolvimento continuamente progressivo, embora lento, das suas disposições originais" (Kant, 1986, p.9). 
questão da justiça diz respeito ao julgar e nós julgamos tendo em vista não apenas o presente e o passado, mas também o futuro. A sociedade não é apenas aquilo que ela já constituiu, o dado presente, mas é aquilo que se está fazendo e o que será feito e por isso inclui, além da sua dimensão sensível, uma dimensão supra-sensível, porque tem em vista o futuro. As opiniões presentes não esgotam toda a realidade, o juízo excede o mero dado, o costume, as opiniões. Assim, podemos dizer que julgamos a partir de uma Idéia que estende o nosso horizonte e que se projeta no futuro, mesmo que não possamos a partir do que apreendemos nela constituir verdadeiramente um conhecimento. Para Kant, ela se apresenta como a Idéia da totalidade dos homens, na forma da humanidade progredindo em direção a uma sociedade de seres livres, ou seja, racionais e responsáveis. Esse progresso não poderia ser apreendido diretamente, mas apenas por signos, como o entusiasmo experimentado pelos espectadores diante da revolução (Lyotard, 1986b).

O problema é que os acontecimentos que marcam nosso tempo nos fornecem signos que, em vez de terem trazido a apresentação da Idéia de uma sociedade cosmopolita e de progresso moral da humanidade, nos colocaram diante de experiências extremamente negativas, que nos ameaçam de diversos modos até hoje. Essas experiências poderiam ser representadas por Auschwitz, simbolizando, para Lyotard, a derrocada da identidade do racional e do real e, com ele, de todo projeto que coloque unidade e totalidade na realidade histórico-política da humanidade (Lyotard apud Benjamin, 1989, p.393). Os signos da atualidade apontam para uma fissão que afeta a totalidade dos discursos unificadores da modernidade. Assim, a Idéia que se projeta no nosso horizonte hoje não é a de unidade e de totalidade da humanidade, mas a de diversidade desses homens e a conseqüência disso é que, a partir dessa Idéia, o domínio prático deixa de poder ser pensado a partir da vontade determinada pela razão e passa a ser pensado a partir do jogo de opinião. Dentro dessa perspectiva, a Idéia de totalidade e de unidade não mais se sustenta, porque não há suporte filosófico para isso, nem na metafísica nem na linguagem. A pragmática da linguagem é entendida aqui como formando uma rede em que há diferentes jogos de linguagem misturados e em relação, mas que nem sempre são unificáveis e, quando não o são, são incomensuráveis, ou seja, carecem de medida comum. Assim, a Idéia que projetamos a partir de uma concepção não unificada da linguagem é a de pluralidade.

A questão então é a de saber se a Idéia de pluralidade pode funcionar como reguladora na nossa prática, fornecendo-nos um horizonte a partir do qual conceberíamos uma noção de justiça. Podemos pensar, por um 
lado, a Idéia de justiça relacionada à de pluralidade, na forma de uma pluralidade de justiças, ou seja, a justiça interna a cada grupo ou sociedade, levando em consideração apenas as regras desse grupo e as relações entre seus participantes, deixando de lado a alteridade existente entre os próprios grupos. Por outro lado, há também a justiça da pluralidade, em que se tem de levar em conta não apenas a heterogeneidade interna da prática de cada grupo, mas também as relações entre os grupos, e essas relações nem sempre permitem unificações (Lyotard, 1983, p.225). É o caso, por exemplo, do conceito de diferendo que vai designar a impossibilidade de unificação de dois tipos de discurso ou de duas instâncias de realidade, sem que haja alteração nas suas respectivas regras. A unificação, nesse caso, só é possível a partir da subordinação de um ao outro. O diferendo, entretanto, não expressa toda relação possível entre partes distintas. Quando há medida comum, devemos falar de litígio e, nesse caso, é possível a unificação sem prejuízo para as partes. A existência de diferendos assinala a ausência de medida comum entre duas ou mais partes referidas, e é o conceito que expressa a impossibilidade de se construir uma teoria universal que unifique e totalize a diversidade da realidade humana. Para exemplificar essa heterogeneidade, consideremos o que ele nos diz sobre as sociedades míticas, caracterizadas pelas narrativas não cosmopolitas.

As sociedades míticas foram compreendidas pelo Ocidente como humanas, na medida em que podiam ser inseridas na história da humanidade a partir de uma visão cosmopolita. Para fazer parte dessa história, no entanto, elas teriam de, além de apresentar seu próprio mundo, apresentar também elementos desse mundo cosmopolita, elas teriam de pressupor a história universal para poder fazer parte dela. Exigir isso, no entanto, seria petição de princípio; há, na verdade, incomensurabilidade entre esses mundos e quando as sociedades míticas são inseridas na história universal, são-no a partir de fora, de algo que lhes é realmente estranho. O selvagem, ao ser julgado e assimilado por um mundo que não é o dele, sofre um dano, uma injustiça (ibidem, p.225). De certo modo, isso é sempre feito e talvez seja inevitável, porque a heterogeneidade não é apenas expressão de mundos incomensuráveis, mas também é expressão da luta e da guerra entre esses mundos e, quando são unificados, isso não é feito de modo harmônico, mas geralmente sob a forma de dominação e um dano é necessariamente cometido contra uma das partes, seja ela assimilada, subordinada ou eliminada pelo outro. A pluralidade de justiças estaria presente uma vez que a heterogeneidade não é eliminada nunca e o que se constata é a coexistência de mundos distintos. 
A Idéia de justiça como pluralismo afirma o reconhecimento da existência de uma pluralidade de justiças a partir do reconhecimento da diversidade das sociedades humanas. Ela supõe a ausência de uma instância totalizadora para fundamentar ou justificar a unificação e vai constituir-se como uma Idéia de valor universal, ao apresentar o reconhecimento da existência de uma pluralidade de justiças, o caráter específico de cada jogo e o reconhecimento da heterogeneidade dos grupos sociais e das culturas. É verdade que a justiça entendida como pluralismo pode levar-nos a uma atitude de indiferença ante as diferenças, quando afirmamos que um grupo é justo desde que respeite suas próprias regras e não procure ter privilégio sobre as outras, nem impor suas regras aos outros. Essa indiferença talvez seja parte inseparável de um pluralismo prático, mas é também sinal de isolamento das partes. E isso sem dúvida não seria suficiente para darmos conta de uma sociedade articulada e não apenas fragmentada. Para Lyotard (1983, p.260), as comunidades fechadas em torno de si mesmas, ou seja, aquelas que resistem a se inserir em uma totalidade cosmopolita e que não reconhecem a universalidade da história, ficam, muitas vezes, presas às suas tradições, cheias de convicções rígidas e não geram verdadeiramente resistências às formas hegemônicas e até em certo sentido as reproduzem.

Partindo do conceito de pluralidade, poderíamos conceber possíveis zonas de conflito, mas também possíveis zonas de entendimento. É sobre a primeira que se dá a guerra e sobre a segunda os acordos. Caso seja possível o acordo, os diferendos ficam ausentes ou deslocados. É preciso, portanto, considerar que há passagens e acordos entre as partes, mesmo que nem sempre, e que é sobre essa possibilidade que se baseia a concepção de um pluralismo que não se reduz simplesmente a um tipo de pluralismo isolacionista e bélico. Não se recusa inteiramente a idéia de um universal, desde que esse se apresente como um universal regulador das diferentes formas de organização da vida humana. O pluralismo, como Idéia, não poderia unificar o diverso sob pena de recair no essencialismo ou no objetivismo dos valores e, assim, na eliminação dos diferendos, mas ele seria capaz de ultrapassar os particularismos, projetando no seu horizonte a coexistência respeitosa das diferenças e o horizonte aberto do porvir.

A Idéia, como pluralidade, é a resposta filosófica para se pensar a justiça em um mundo que paradoxalmente vive sob uma forma hegemônica de dominação, a do capital, que determina, em diversos níveis, a relação entre os homens. Nesse sentido, ela tem um papel positivo, que é o de servir de meio de resistência a toda unificação imposta, pois não 
apresenta nenhum conteúdo unificado, bem como não tem o poder de expressar formalmente uma legislação universal. Ela certamente não elimina o conflito das partes e por isso não se propõe a eliminar o jogo de poder e as relações que este mantém com o conhecimento, mas torna isso explícito e, se não é capaz de evitar as formas de dominação e de injustiça existentes nesse mundo, também não cria a ilusão de que o conflito poderia ser eliminado de vez pelos processos de unificação e de universalização dos valores, o que seria a mais alta forma de se exercer a dominação. A Idéia de pluralidade tem a função de expressar a aceitação da existência do outro e de sua absoluta alteridade e, a partir daí, abrir a possibilidade de negociação ou de acordo com ele, sem, necessariamente, ter de ser estabelecida uma relação de dominação. Além disso, ajudaria a evitar o terror e o totalitarismo, formas supremas de injustiça, em que há a negação absoluta do outro. O outro, que não é apenas aquele que, por ser existente e distinto, nós podemos reconhecer e recusar, mas é também o que ainda não está dado, o que não tem existência, é um mundo possível, a imprevisibilidade do futuro.

CHEDIAK, K. Plurality as regulatory idea: the concept of justice according to Lyotard. Trans/Form/Ação (São Paulo), v.24, p.213-224, 2001.

- ABSTRACT: According to Lyotard we can no more support our universal values in any philosophical system. Plurality is the greatest sign of our time and we should think of justice based on it and not against it. It doesn't mean reducing the justice question to opinion games or power relations, but it means conceive it based on an Idea, whose universality and finality are exactly the Idea of coexistence of difference and it would have a regulatory function over the diversity of opinions. The Idea of plurality can have an important function, because when we judge, we don't consider only the present, we also consider what we wish for the future of human beings and the world. If this Idea can't unify our values and assure peace, it can at least help us avoid the confusion between unity or universality and domination and claim the coexistence of differences.

- KEYWORDS: Justice; Kant; Lyotard; plurality.

\section{Referências bibliográficas}

BENJAMIN, A. (Ed.) The Lyotard reader. Oxford: Blackwell, 1989. 
BOBBIO, N. Igualdade e liberdade. Trad. Carlos Nelson Coutinho. Rio de Janeiro: Ediouro, 1996.

KANT, I. Idéia de uma história universal de um ponto de vista cosmopolita. Trad. Rodrigo Naves e Ricardo Terra. São Paulo: Brasiliense, 1986.

LYOTARD, J. F. Le différend. Paris: Minuit, 1983.

. O pós-moderno. Trad. Ricardo Corrêa Barbosa. Rio de Janeiro: J. Olympio, 1986a.

. L'enthousiasme: la critique kantienne de l'histoire. Paris: Galilée, $1986 \mathrm{~b}$.

. O pós-moderno explicado às crianças. Lisboa: Dom Quixote, 1987.

LYOTARD, J. F., THÉBAUD, J. L. Just Gaming. Minneapolis: University of Minnesota, 1985.

MAY, T. Kant the liberal, Kant the anarchist: Rawls and Lyotard on kantian justice. The Southern Journal of Philosophy, v.28, n.4, 1990.

. The Political Philosophy of Poststructuralist Anarchism. Pennsylvania: Pennsylvania Press, 1994.

TERRA, R. A política tensa: idéia e realidade na filosofia da história de Kant. São Paulo: Iluminuras, 1995. 